\title{
ASPECTOS DE LA ECONOMÍA DEL CONVENTO SAN AGUSTÍN DE CÁDIZ
}

(1750 - 1835)

\section{ISMAEL AREVALILLO GARCÍA, OSA \\ CENTRO TEOLÓGICO SAN AGUSTÍN UNIVERSIDAD PONTIFICIA DE SALAMANCA}

RESUMEN: A lo largo de estas páginas, pretendo ofrecer al lector una aportación que le permita conocer los aspectos económicos del convento San Agustín de Cádiz (1750 - 1835), regentado por los agustinos calzados. Como todos los monasterios de la época, fue dueño de fincas rústicas y de cuantiosas propiedades urbanas, que con el correr de los años - hasta la llegada de las desamortizaciones - fueron aumentando en número, debido en parte a la mentalidad religiosa de la época y que hicieron necesaria una buena administración que garantizase la subsistencia conventual.

PALABRAS CLAVES: agustinos calzados, beneficios, rentas, censos, convento.

\section{ASPECTS OF THE ECONOMY OF THE SAINT AUGUSTINE'S PRIORY OF CÁDIZ (1750 - 1835)}

\begin{abstract}
Throughout these pages, I intend to offer the reader a contribution that allows you to know the economic aspects of the Saint Augustine's priory of Cádiz (1750 - 1835), run by the augustinian friars. Like all the monasteries of the time, it was the owner of rustic extensions and of numerous urban properties, that with the passage of the years - until the arrival of the confiscations - they were increasing in number, due partly to the religious mentality of the time and that they made necessary a good administration that guaranteed the conventual subsistence.
\end{abstract}

KEYWORDS: augustinian friars, benefits, rents, censuses, priory.

\section{SIGLAS:}

AHN: Archivo Histórico Nacional.

ADCA: Archivo Diocesano de Cádiz.

AHPCa: Archivo Histórico Provincial de Cádiz.

AGS. CERG: Archivo General de Simancas. Catastro de Ensenada. Respuestas Generales.

AMChF. Archivo Municipal de Chiclana de la Frontera (Cádiz). 


\section{Introducción}

Lo primero que debemos tener en cuenta a la hora de estudiar cualquier aspecto de un convento, es tener bien claro que cada uno de ellos posee unas características determinadas por su fecha, lugar de fundación, su patrimonio dotal, el origen social de sus integrantes, sus relaciones con el entorno, las condiciones de patronato y la política de los diferentes superiores ${ }^{1}$.

Desde su fundación, el convento San Agustín de Cádiz se fue convirtiendo en un centro económico muy importante. Sus extensas propiedades - sobre todos bienes urbanos proporcionaron a la comunidad religiosa abundantes rentas y beneficios, llegándose a convertir en el convento más rico de toda la ciudad. Esta situación obligó a los agustinos calzados al ejercicio de una notable actividad económica. Quehacer que permaneció hasta que las leyes desamortizadoras de Mendizábal pusieron fin a la presencia de estos frailes en la ciudad de Cádiz, pues sus bienes - incluido el convento - salieron a pública subasta, como también he anotado en esta investigación.

El objetivo de esta investigación, es presentar un estudio de los aspectos económicos (propiedades conventuales y rentabilidad de las mismas, ingresos y gastos) del convento San Agustín de Cádiz, concretamente desde el año 1750 hasta la llegada de las desamortizaciones en 1835. Para abarcar tal propósito he recurrido a fuentes primarias como Libros Becerros, Apeos, legajos que contienen escrituras y donaciones de haberes conventuales e inventarios de bienes realizados en el siglo XIX. Asimismo, apoyo el texto con una seleccionada bibliografía referente a la cuestión que trato.

\section{Fundación del convento}

La presencia conventual en Cádiz obedeció a que la ciudad ofreció muchas garantías y un gran atractivo para dar origen nuevas casas religiosas: fue puente de enlace entre el Nuevo y el Viejo Mundo, se convirtió en un gran núcleo poblacional y lugar de trata de valiosas y caudalosas mercancías. Hasta bien entrado el siglo XVI, no hubo ningún convento de religiosos, bien por descuido de los moradores de la ciudad o por ser tan corta la Isla ${ }^{2}$.

\footnotetext{
1 SORIANO TRIGUERO, Carmen: "La propiedad inmobiliaria de los conventos femeninos madrileños del siglo XVIII". Cuadernos de Historia Moderna, 24, 2000, p. 24.

2 MORGADO GARCÍA, Arturo: La diócesis de Cádiæ: De Trento a la desamortización, Cádiz, Servicio de Publicaciones de la Universidad de Cádiz, 2008, pp. 83 - 132.
} 
Según nos relata en su Historia de Cádir, Agustín de Orozco, la falta de conventos fue suplida con la presencia de hombres muy cultos y letrados de todas las Órdenes que misionaron, confesaron y predicaron en los tiempos convenientes, sacando por ello una buena limosna ${ }^{3}$.

Los primeros religiosos que llegaron a Cádiz con intención de fundar fueron los jesuitas, en el año 1564. Éstos, con la benevolencia de los cabildos eclesiásticos y los regidores comenzaron su andadura, siendo ayudados para su sustento ordinario, puesto que eran pobres, con gran cantidad de limosnas. Obtenidas las licencias para la fundación, mencionadas autoridades y muchos particulares les donaron en los primeros años 400 ducados repartidos de la siguiente manera: 200 el cabildo eclesiástico, 150 el de la ciudad y el resto distintos individuos. Con tan gran magnanimidad y siendo provincial de la Provincia Jesuita de Andalucía el P. Juan Plaza, junto con el P. Diego López, primer prior de colegio, se inició la presencia de la Compañía en Cádiz a partir del uno de abril de 1564, junto a la ermita de Santiago, situada en un entorno privilegiado de la ciudad y de bella factura. Llegaron a vivir en esta casa hasta veinte religiosos dedicados a la instrucción de la juventud y permanentemente socorridos con las limosnas que les dieron ${ }^{4}$.

El segundo gran convento que existió en Cádiz antes del establecimiento de los agustinos fue el de San Francisco. El punto de arranque estuvo en Fray Juan Navarro, natural de la ciudad de Antequera, hombre muy docto y experto fundador de casas religiosas, quien habiéndose percatado de la buena disposición de las autoridades para establecer un convento, comenzó los trámites. Algunos particulares le dieron ocho aranzadas de tierra y 400 ducados para que se pudieran labrar, a esto se sumaron otros 600 ducados procedentes de limosnas. Con esta ayuda levantó los cimientos de la iglesia conventual el día 25 de marzo de 1566. El primer cuerpo del templo fue de tablas y muy pequeño, pero con el paso de los años toda la edificación llegó a tener un gran esplendor en la que trabajaron los mejores maestros, de tal manera que fue la casa más apetecida por los religiosos de esta Orden después de la Sevilla ${ }^{5}$.

Por los que respecta a los agustinos, el libro de clero 1773 conservado en el AHN, nos detalla el establecimiento de estos frailes en la ciudad, la fundación conventual y la construcción de las diversas dependencias monacales. Según el manuscrito, el estratégico lugar que ocupó Cádiz - como ya he indicado - hizo que muchos de ellos acudieran a la ciudad para pasar a Indias con el fin de instruir en la fe a los moradores de aquellas tierras. Hasta que embarcaban, estos religiosos pasaban días por la ciudad pidiendo limosna hasta que la flota se armaba. Durante este tiempo se hospedaban en posadas y casas indignas a su

\footnotetext{
3 DE OROZCO, Agustín: Historia de la Ciudad de Cádir, Cádiz, Ayuntamiento de Cádiz, 1845, p. 258.

${ }^{4}$ Ibid., pp. $261-262$.

5 Ibid., pp. 259 - 260.
} 
condición. Por este motivo, en el año 1593 Felipe Voquín de Bocanegra, regidor de la ciudad y gran devoto de San Agustín, donó un solar en la Plaza de la Candelaria a los agustinos de la Provincia de Andalucía para que fundasen un convento e iglesia, dándoles 100 fanegas de trigo cada año. En virtud de esta dádiva, el P. Provincial Francisco de Castro, envió al prior de Vejer, P. Antonio Enríquez, para que tomase posesión. Esta primera fundación sucedió el 2 de abril de 1593.

Dicho acto no se pudo llevar a cabo de manera pacífica, pues tras la toma de posesión, el tesorero de la catedral y regidor eclesiástico Cristóbal Martín y los regidores civiles Diego Villar y Bartolomé de Anaya, solicitaron se despojase a los agustinos de la donación recibida. La tensión creada entre ambas facciones fue tan tensa, que éstos últimos fueron llevados al puerto montados en un barco y expulsados a El Puerto de Santa María. Con la llegada de las tropas inglesas a Cádiz en el año 1596, la ciudad sufrió un gran saqueo: se arruinaron muchos edificios y se incendiaron cuantiosas iglesias. Ante tal panorama, la desilusión se apoderó del ánimo de los fundadores de tal manera, que no se volvió a considerar el asunto hasta veintiún años después. Durante este tiempo la ciudad se reformó y se reedificaron los edificios. A esto, se añadieron los hechos de que algunos de los antiguos opositores a la fundación fallecieron y al haberse realizado un nuevo trazado de la ciudad, la ubicación de las primitivas casas también varió.

Dadas estas circunstancias, en el año 1617 se reconsideró de nuevo la cuestión fundacional siendo provincial de Andalucía Fr. Pedro Ramírez. Habiendo obtenido las licencias reales para proceder a tal acto, éste presentó el documento a Juan Espinosa, escribano público de Cádiz y, con fecha del 29 de septiembre de 1617, los veinte regidores congregados autorizaron la fundación. Un mes más tarde, Fr. Antonio Granillo y Fr. Luis Enríquez se presentaron ante el señor obispo solicitándole las casas que en su día les cedió Felipe Voquín de Bocanegra, a lo que el prelado les respondió que tal pretensión no era posible, pero accedió a que se estableciesen en otro lugar de la ciudad. Ante tal circunstancia, los agustinos se encontraron sin lugar para fundar. Fue el regidor y capitán Lorenzo de Herrera Vetancor, quien les vendió el 23 de noviembre de 1617 unas casas que tenía en la Plazuela de Pedro Vidal. Días después, ante los doctores Alonso Gómez de Mendoza, canónigo magistral de la Catedral; Hernán Sánchez de Alma y el capitán Lorenzo de Herrera, caballero de hábito de Cristo y los regidores de Cádiz, los agustinos presentaron a los presentes la provisión real y tomaron posesión de las casas.

Este acto se comenzó con el traslado del Santísimo con toda solemnidad, poniéndose a continuación una campana. Después, se dio lectura a una carta del P. Provincial en la que 
constituyó la primera comunidad agustiniana de Cádiz el día 8 de diciembre de 1617 con los siguientes hermanos: Fr. Guillermo de Cabañas, prior; Fr. Diego Torres, subprior; Fr. Nicolás de Santa María, sacristán; Fr. Juan Enríquez y Fr. Agustín Guerrero. Tras su llegada y asentamiento en la ciudad, fueron a visitar al obispo, "quien les recibió con mucha benignidad y cariño", como también lo hicieron el corregidor, los cabildos y muchos vecinos, dándoles a entender que todos ellos estuvieron muy alegres por la nueva fundación. Dentro de este ambiente de mutua cordialidad, la nueva comunidad religiosa procesionó junto a los cabildos en la procesión que salió desde la iglesia mayor al convento de las religiosas de Santa María. Este fue el primer acto de los agustinos en la ciudad de Cádiz.

Por tanto, a la luz que nos ofrecen los documentos, se puede afirmar lo siguiente: primeramente los agustinos se establecieron el 2 de abril de 1593 en un solar que les fue donado, pero debido a la adversidad que encontraron por parte de las autoridades mencionadas anteriormente, tuvieron que abandonar la ciudad. En un segundo momento, los agustinos obtuvieron permiso para fundar un convento el 29 de septiembre de 1617, se empezó a edificar sobre unas casas en la Plazuela de Pedro Vidal a fecha de 23 de noviembre de 1617, y quinde días más tarde ya vivió allí la primera comunidad. Con el paso del tiempo esta edificación se fue consolidando y agrandando mediante la anexión de edificios colindantes.

Pero esta nueva fundación no se libró tampoco de la polémica, en este caso venida de la mano de los padres franciscanos, quienes en febrero de 1618 les pusieron un pleito, puesto que según ellos los agustinos se habían establecido en un lugar que les perjudicaba. Para proceder a tal demanda, los franciscanos se basaron en unas letras apostólicas que les fueron concedidas, según las cuales nadie podía fundar nuevos conventos en los sitios en los que sus limosnas resultasen agraviadas; y los agustinos habían empezado a levantar el suyo muy próximo. El pleito se tuvo que resolver en la Real Audiencia de Sevilla, cuya sentencia fue posteriormente confirmada por el Nuncio Apostólico.

Resuelto el litigio, se prosiguió con la fundación sobre las casas vendidas por el capitán Lorenzo Herrera Ventacor en el precio de 2.200 ducados y con la obligación de darle una capilla que conllevó las siguientes condiciones:

1. La primera que en la capilla Mayor no se debería hacer más altar que el del presbiterio.

2. El púlpito se debería poner frente a su capilla.

3. El día de su entierro y el de su sucesor, se debería poner en la capilla Mayor un frontal de luto donde se expusiera su cuerpo y el de su sucesor. 
Para continuar con las obras del convento, se compraron a Luis de la Puente cuatro casas más en la Plazuela de Vidal, por 1.800 reales de plata. Esto sucedió el día 2 de mayo de 1619. El espacio se utilizó para la iglesia. Una vez levantadas tres paredes del templo, que fueron la de la parte del claustro, la cabecera del altar mayor y la de la puerta principal, faltó una cuarta, que fue la que dio a una plazuela, cuyo espacio se hizo muy necesario para la ampliación de la iglesia y poder hacerla de más bella factura. Vista la necesidad, se solicitó al Rey tal concesión, merced que concedió el monarca Felipe IV por Cédula Real el 16 de septiembre de 1644, además de 150 ducados.

El 7 de julio de 1642, el doctor García López de Cabra vendió a la comunidad religiosa dos casas que fueron de Correos. Seis años más tarde, se siguió ampliando el edificio conventual con la adquisición de unas casas ubicadas en la calle San Francisco, lindando a uno de los muros de la iglesia y que fueron farmacia. Los agustinos las compraron a Manuel de Yriberri por el precio de 17.000 reales de vellón. En la amplitud de estos solares se pudo levantar parte del claustro, la portería y un aposento debajo de la escalera que después fue la tienda del barrero. Poco tiempo después, se incorporó al complejo monacal varias casas compradas a Diego Fernández de Villalón y María de Casanova, su mujer, y a María de Casanova, la madre ésta. Más moradas, todas juntas, que pertenecieron a Francisco Martín de Lara y al licenciado García López de Cabra; todas ellas en el precio de 1.300 ducados de vellón. Y de esta manera se fue consolidando y agrandando el convento: se hizo la cocina, el refectorio, celdas, el noviciado y en la parte baja se hizo una bodega. Las casas del Correo se usaron para el segundo claustro.

El claustro principal, muy hermoso, tuvo veinte columnas de piedra blanca de Génova que sujetaron dos galerías. El convento poseyó una biblioteca, una torre descubierta desde la que se divisó toda la ciudad y dos escaleras con barandilla de hierro y con hermosos azulejos. Los ángulos del claustro bajo estuvieron decorados con cuadros de San Agustín, San Guillermo, San Nicolás de Tolentino y Santo Tomás de Villanueva. Mencionado claustro, estuvo embaldosado con piedra de Génova y contó con un aljibe con brocales de piedra

La sacristía se construyó al mismo tiempo que la iglesia. Fue espléndida por sus alhajas, cajonería, pinturas y molduras. Tuvo oratorio con retablo, altar y varias reliquias de gran veneración.

A la par que se fue edificando la iglesia, como fue costumbre en aquella mentalidad tan religiosa, la gente más noble y selecta de la ciudad compró su capilla por una cuantiosa cantidad pecuniaria. El patronato y la capilla Mayor fueron titularidad de Manuel de Yriberri. El patrocinio fue confirmado por el Capítulo Provincial celebrado en el convento de Córdoba en julio de 1646. Muerto éste y, sin descendencia, la comunidad quedó de nuevo 
como dueña del patronato en febrero de 1659. Éste fue ofrecido a Diego Centeno, caballero de la Orden de Santiago y gran benefactor. Tras su fallecimiento, el día 9 de febrero de 1795, recayó en la Cofradía de la Humildad, quien entregó al convento 9.000 ducados.

En el interior del templo se construyeron un total de nueve capillas: Tránsito de Nuestra Señora, San Lorenzo y San Juan Bautista, Santo Tomás de Villanueva, Santo Cristo de la Humildad, Santa Rita, La Concepción, Capilla de los Galafates, Nuestra Señora de Regla y Capilla de la Congregación. Todas ellas tuvieron sus patronos o titulares, que las adquirieron por compra ${ }^{6}$.

Con el paso de tiempo la comunidad religiosa se fue consolidando, siendo una de las más numerosas de la Provincia de Andalucía, por detrás de la del convento San Agustín de Sevilla. El Catastro de Ensenada en sus Respuestas Generales, nos dice que a fecha de 5 de mayo de 1753, la comunidad estuvo formada por 84 agustinos ${ }^{7}$.Según nos indica Basilio Estrada en su estudio, en el año 1808 la comunidad tuvo 65 religiosos, en 1828, 40 y en 1834, $28^{8}$. Hubo en esta casa noviciado, estudios de Matemáticas, Filosofía y Teología, con tres maestros: regente de estudios, lector y pro - lector'.

Ante las turbulencias políticas y militares de inicios del siglo XIX, el culto continuó, en su interior se hospedaron soldados nacionales y la comunidad contribuyó con fuertes sumas de dinero a sostener al gobierno nacional ${ }^{10}$.

Pascual Madoz en su Diccionario Histórico - Geográfico, menciona que en el año 1846 el convento era colegio de segunda enseñanza y que la iglesia seguía abierta al público ${ }^{11}$.

\section{La economía del convento san Agustín de Cádiz (1750 - 1835)}

La economía de un monasterio puede verse desde dos aspectos muy diferentes. Por un lado, el cenobio, como tal, con una estructura económica simple, como un hogar en el que viven diferentes personas que tienen unas necesidades concretas. Y por otro, el monasterio como un auténtico señor feudal, con grades propiedades - tierras, viñas, casas que le proporcionan muchas rentas, las cuales necesariamente necesitaron ser administradas ${ }^{12}$.

\footnotetext{
${ }^{6}$ AHN. Clero. Secular - regular, libro1773, ff. 1v - 19v. En este documento se relata toda la fundación del convento san Agustín de Cádiz, tal y como he descrito en el texto. Véase también ADCA. Cédulas fundaciones. Convento San Agustín.

7 AGS. CERG. Libro 561. Imagen 0116.

${ }^{8}$ ESTRADA ROBLES, Basilio: Los agustinos ermitaños en la España hasta el siglo XIX, Madrid, Editorial Revista Agustiniana, 1988, p. 484.

9 CANTO, Nicolás: “Conventos de la Provincia de Andalucía en 1834”, Archivo Agustiniano, IX,1918, p. 66 10 Ibid., p. 418.

${ }_{11}$ MADOZ, Pacual: Diccionario Geográfico - Estadístico - Histórico de España y sus posesiones de Ultramar, V, Madrid, Imprenta Nacional, 1846, p. 173.

12 MIRANDA MENACHO, VeraCruz: "Algunos aspectos de la economía del monasterio de Pedralbes a través del Manual (1414 - 1419) y del Capbreu (1414 - 1418) de Gabriel de Forest”. Anuario de Estudios Medievales 33/1, 2003, p. 176.
} 
Si analizamos este primer aspecto, el convento de San Agustín de Cádiz, entendido como una vivienda, que necesitó sus propios trabajadores, podemos darnos cuenta de que los religiosos contaron con un determinado número de trabajadores que pudieron ocuparse de su funcionamiento interno. Analizando el libro gasto 1794, conservado en el AHN, sección Clero, observamos cómo la comunidad de agustinos tuvo contratadas a diversas personas extrañas al monasterio que cubrieron los servicios domésticos: lavanderas, mozos ayudantes de cocina, porteros, escribanos; así como diversas necesidades personales de los religiosos, sobre todo el médico y el cirujano. En las cuentas que se anotaron en este libro, se hace referencia a los salarios que cobraron estos empleados domésticos - generalmente en función de la categoría de su oficio -, al mismo tiempo, que nos permiten percatarnos de que algunos de ellos tuvieron un carácter temporal en virtud de las necesidades, y otros fijos desde el punto de vista laboral. La lavandera, por ejemplo, fue una empleada estable, y sus honorarios en el año 1830 fueron de 200 reales de vellón mensuales. El médico también tuvo carácter fijo y cada vez que acudió al convento percibió 6 reales de vellón. Por el contario, los escribanos y los mozos ayudantes solo cobraron cuando fue necesario su trabajo. Para hacernos una idea en conjunto de los salarios conventuales en el mencionado año1830, el total de todos ellos fue de 760 reales de vellón, excluyendo a la lavandera ${ }^{13}$.

Expongo un ejemplo basado el libro de gasto correspondiente al año $1754^{14}$, y que hacen referencia a los gastos de manutención y vida cotidiana de la comunidad religiosa:

\section{Cuadro 1}

Gastos de los religiosos agustinos de Cádiz entre el 9 y el 16 de julio de 1754

\begin{tabular}{|c|c|}
\hline Concepto & Gasto ( $\boldsymbol{r s}$. $\boldsymbol{\text { mrs.}}$.) \\
\hline Ropa & 10 \\
\hline Cartas & 72,30 \\
\hline Hábitos & 15 \\
\hline Nieve & 008 \\
\hline Berzas & 20,8 \\
\hline Gallina & 7,22 \\
\hline Manteca & 3,26 \\
\hline Ensalada & 3,6 \\
\hline Escobas & 4,4 \\
\hline Papel & 46 \\
\hline Tinta & 6,4 \\
\hline Chocolate & 164,24 \\
\hline Libro & 90 \\
\hline Fruta & 24,42 \\
\hline Pescado & 10,12 \\
\hline Huevos & 3,18 \\
\hline Tomate & 28,28 \\
\hline &
\end{tabular}

13 ANH. Clero. Secular - regular, libro 1794.

14 AHN. Clero. Secular - regular, libro 1774. 
Centrándonos el segundo aspecto - el monasterio como un auténtico señor feudal los agustinos de Cádiz detentaron gran cantidad de bienes urbanos: casas, accesorias y tiendas en las principales calles del casco urbano y en otros pueblos, como Chiclana de la Frontera; propiedades rústicas, como fue la hacienda de San Fernando (Real Isla del León); censos y otra clase de bienes procedentes de su condición de casa religiosa (Memorias, aniversarios, diversas celebraciones religiosas...), que propiciaron sustanciosas cantidades pecuniarias a las arcas conventuales, permitiendo de esta manera no solo la subsistencia de la comunidad, sino también la conservación y embellecimiento del edificio conventual. En otro apartado de este trabajo haré referencia a los ingresos que proporcionaron a los religiosos todos estos bienes.

Para la administración de estos haberes, la comunidad religiosa nombró a un religioso que asumiera el cargo de administrador, el cual fue anotando en el libro de cuentas todas las entradas y salidas de una manera minuciosa. Cada tres años, que es lo que duraba el mandato de un prior, se hacía el balance global del trienio, el cual quedaba reflejado en los libros de contabilidad. Éstos, a su vez, fueron revisados y aprobados por el P. Provincial cuando visitó a la comunidad ${ }^{15}$.

\subsection{El patrimonio del convento San Agustín de Cádiz}

El patrimonio del convento San Agustín de Cádiz fue inmenso. Los libros de clero custodiados en el AHN - ya mencionados - , y los inventarios de bienes que se elaboraron con motivo de la desamortización de Mendizábal, son un máximo exponente de la gran cantidad de pertenencias que tuvo el convento, las cuales fueron rentabilizadas por los religiosos de tal manera que el beneficio obtenido permitió no sólo la subsistencia comunitaria, sino también la ampliación y conservación de toda la hacienda.

La primera pregunta que nos puede surgir es la siguiente: ¿Cómo lograron hacerse estos religiosos con un patrimonio tan inmenso? La respuesta está íntimamente relacionada con la importancia de la presencia de los agustinos en todos los aspectos de la vida cotidiana. A partir de Trento, se acentuó lo que se ha denominado la "religiosidad de la presencia social", y en esta tarea, las órdenes mendicantes y los clérigos regulares fueron protagonistas evidentes. La religiosidad tridentina potenciaría las penitencias, las rogativas y procesiones, la valoración de las misas por los difuntos, el culto y la devoción a los santos y a sus reliquias...,

${ }^{15}$ En el AHN. Clero. Secular - regular, se conservan varios Libros Becerros del convento: 1780, 1795, 1798, $1799,1788,1791,1774,1779$, en los que queda reflejada de una manera muy precisa la afirmación del texto. 
no solo como como defensa de catolicismo, sino también como medio de irradiación social, pues de su influencia social dependió su supervivencia económica ${ }^{16}$.

Gran parte de la fortuna conventual fue adquirida con capitales procedentes de fundaciones religiosas. $\mathrm{Y}$ aquí es donde apareció uno de los asuntos más rentables del entramado de las creencias religiosas: la cuestión de la muerte ${ }^{17}$. El protagonismo que tuvieron los eclesiásticos en los rituales funerarios se fue desarrollando progresivamente hasta degenerar en un auténtico negocio con una religiosidad que potenció las manifestaciones externas de piedad hasta en la muerte. Muchas de las fundaciones religiosas estuvieron relacionadas con la cuestión del final de la vida: misas, aniversarios perpetuos, fiestas, Memorias.... resultaron notas comunes en los feligreses y proliferaron en los testamentos, donde todos en mayor o en menor medida consignaron determinadas cantidades al pago de los sufragios y de los servicios religiosos de carácter perpetuo ${ }^{18}$.

Según se constata en los testamentos y escrituras de donación, la satisfacción que recibieron los frailes por estas fundaciones religiosas pudo ser en metálico y en forma de donación de un bien - rústico o urbano - por parte del testador. Estas herencias, en la mayoría de los casos muy sustanciosas, generalmente fueron reinvertidas en la ampliación de su patrimonio. De ahí, que el aumento de la riqueza viniera también por otras vías: compra directa, ventas, censos y trueques, ya que los religiosos poseyeron dinero procedente de las donaciones anteriormente mencionadas. Expongo varios ejemplos al respecto.

Para la edificación y engrandecimiento de edifico conventual, los agustinos fueron comprando varias casas: la primera a Luis de la Puente, la segunda a Francisco Martín de Lora, la tercera al doctor García López de Cabra y la cuarta al Martín de Ayzare, correo mayor de la ciudad ${ }^{19}$.

Cuando se levantó la iglesia del convento, la comunidad ofertó varias capillas ubicadas en los laterales del templo. Fueron adquiridas por personas y cofradías, muy estimadas y consideradas en la ciudad de Cádiz, que se convirtieron en sus patronos. Estos espacios fueron utilizados para sus enterramientos y el de sus descendientes. A cambio se pagaron elevadas cantidades de dinero. Señalo las capillas y su localización ${ }^{20}$.

\footnotetext{
16 ATIENZA LÓPEZ, Ángela: "La expansión del clero regular en Aragón durante la Edad Moderna. El proceso fundacional". Anuario de Historia Moderna 21, 2000, pp. 18 - 19.

17 Para más información sobre el tema véase ARIES, Philippe: El hombre ante la muerte, Madrid, Taurus, 1987.

18 ATIENZA LÓPEZ, Ángela: Propiedad y señorío en Aragón. El clero regular ante la expansión de la crisis (1700 1835), Zaragoza, Institución Fernando el Católico, 1993, pp. 47 - 48.

19 AHN. Clero. Secular - regular, libro 1804. Este libro contiene los títulos de propiedad de las cuatro casas.

${ }^{20}$ AHN. Clero. Secular - regular, libro 1773, ff. 20v - 25v. También en AHN. Clero. Secular - regular, libro

1808. En esta fuente se conservan las escrituras de venta de algunas de estas capillas.
} 


\section{Cuadro 2}

\section{Capillas del convento San Agustín de Cádiz}

\begin{tabular}{|c|c|c|}
\hline Capilla & Comprador & Importe \\
\hline $\begin{array}{c}\text { Capilla del Tránsito de } \\
\text { Nuestra Señora: colateral al } \\
\text { lado de la epístola }\end{array}$ & $\begin{array}{l}\text { José Pinto, vecino de Cádiz, } \\
\text { para sí y sus herederos. El } \\
\text { susodicho la vendió la mitad } \\
\text { de este patronato al capitán } \\
\text { Nicolás Rufo, regidor de } \\
\text { Cádiz }\end{array}$ & $\begin{array}{l}2197 \text { ducados } \\
2000 \text { ducados }\end{array}$ \\
\hline $\begin{array}{c}\text { Capilla de Santo Tomás de } \\
\text { Villanueva: al lado del } \\
\text { Evangelio, junto a la de San } \\
\text { Juan Bautista }\end{array}$ & $\begin{array}{c}\text { Bartolomé Márquez y } \\
\text { Francisca María del Castillo, } \\
\text { su mujer, a sus herederos y } \\
\text { sucesores por } 1.000 \text { ducados }\end{array}$ & $\begin{array}{c}1000 \text { ducados } \\
26 \text { de agosto de } 1677\end{array}$ \\
\hline $\begin{array}{c}\text { Capilla de Santa Rita: la } \\
\text { primera al lado de la epístola }\end{array}$ & Alberto Martín & 1400 ducados \\
\hline $\begin{array}{l}\text { Capilla de la Concepción: } \\
\text { entre la anterior y la puerta } \\
\text { de la iglesia. En esta capilla } \\
\text { se colocó una bella imagen } \\
\text { de Nra. Sra. de los Dolores }\end{array}$ & Manuel Barrios y sucesores & $\begin{array}{c}5000 \text { ducados } \\
1775\end{array}$ \\
\hline $\begin{array}{c}\text { Capilla de los Galafates: } \\
\text { entregada a los maestros } \\
\text { galafates de la ciudad }\end{array}$ & $\begin{array}{c}\text { Entregada a los galafates de } \\
\text { la ciudad }\end{array}$ & $\begin{array}{l}1100 \text { ducados } \\
\text { Enero de } 1665\end{array}$ \\
\hline Capilla de la Congregación & $\begin{array}{c}\text { Esclavos del Santísimo } \\
\text { Sacramento }\end{array}$ & $\begin{array}{c}2000 \text { ducados } \\
8 \text { de octubre de } 1667\end{array}$ \\
\hline
\end{tabular}

Las donaciones, sin más, también proliferaron en los testamentos. Así, por ejemplo, heredó la comunidad religiosa una casa y capellanía en la Plaza de San Antonio a la muerte del capellán Pablo Álvarez Pimentel, presbítero y abogado en El Puerto de Santa María. Esta capellanía fue fundada por Pedro de la Cuesta en 1675, según consta en la escritura de fundación del 10 de enero de dicho año ${ }^{21}$.

Los censos o tributos impuestos sobre diversas clases de bienes también fueron muy comunes. En el pueblo de Chiclana de la Frontera tuvieron un censo sobre una casa ubicada en la calle Araja, legado por Juan Bautista y su mujer ${ }^{22}$.

Y, por supuesto, fueron las celebraciones religiosas - haré de nuevo referencia a ellas en el siguiente apartado de este trabajo - quienes también contribuyeron de una manera muy generosa a la dilatación de la riqueza conventual, pues fueron muchas y de variada índole. Sirva como referencia el año 1826, en el que la comunidad tuvo la obligación de decir 651 misas cantadas, 1.574 rezadas y 33 vigilias; todas con su correspondiente limosna ${ }^{23}$.

\footnotetext{
21 AHN. Clero. Secular - regular, libro 1508.

22 AMChF. Catastro del Marqués de la Ensenada. Provincia de Cádiz. Municipio de Chiclana de la Frontera. Bienes Eclesiásticos. Sign. 00342, f.55r.

${ }^{23}$ AHN. Clero. Secular - regular, libro 1794, f. 85r.
} 
Por tanto, fueron las fundaciones religiosas, la compra directa, las donaciones y las limosnas, las vías comunes por las que se fue configurando con el transcurrir del tiempo toda la hacienda conventual.

\subsection{La explotación y rentabilidad del patrimonio del convento San Agustín de Cádiz: los ingresos}

Se puede decir que los ingresos de este convento agustino procedieron sobre todo de cuatro sectores bien distintos: la propiedad urbana, la propiedad rústica y los censos y treudos. El orden en importancia fue: primero las casas, después los censos y los campos. Este rango lo establezco a partir de que la importancia del patrimonio eclesiástico se estableció dependiendo del volumen de rentas que generaron ${ }^{24}$. Un cuarto grupo estuvo formado por los ingresos procedentes de los servicios religiosos y de las limosnas, consecuencia todo ello de una sociedad impregnada de un fuerte espíritu religioso (aniversarios, misas, novenas, acompañamientos...), que a partir del siglo XVIII comenzaron a disminuir ${ }^{25}$.

a) Bienes urbanos.

La posesión de estos inmuebles por parte del clero regular fue una práctica común en todos los conventos. Ángela Atienza en su estudio sobre las propiedades del clero regular en Aragón, indica cómo en el siglo XVIII los regulares residentes en Zaragoza controlaron el $17 \%$ de este tipo de bienes ${ }^{26}$. Fueron, sin duda, esta clase de bienes los más cuantiosos y los que generaron mayores ingresos en las cuentas conventuales de Cádiz. Estos inmuebles de carácter urbano, generalmente casas, pero también algún solar, se explotaron por el régimen de alquiler. Las casas para habitación adquirieron singular importancia en las ciudades y los pueblos grandes, pues solieron estar situadas en los mejores barrios ${ }^{27}$.

${ }^{24}$ SAAVEDRA, Pegerto: "El control de los patrimonios eclesiásticos en la Galicia Moderna". Historia Agraria 74, 2018, p. 11.

25 MARTINEZ RUIZ, Enrique: El peso de la Iglesia. Cuatro siglos de órdenes religiosas en España, Madrid, Actas, 2004, pp. 289 - 356. En este capítulo recoge un estudio dedicado a la economía de las órdenes religiosas en la Edad Moderna, destacando aspectos como la formación del patrimonio, la gestión y evolución de la economía en el clero regular. Puede consultarse también LÓPEZ OLLERO, María Ángela: Los bienes del clero regular en la provincia de Cádiz en vísperas de la desamortización de Mendizábal [Tesis doctoral leída en la Universidad de Sevilla], 1999. SÁNCHEZ MECO, Gregorio: Ell Escorial y la orden jerónima. Análisis económico - social de una comunidad religiosa, Madrid, Patrimonio Nacional, 1985.

26 ATIENZA LÓPEZ, Ángela: Propiedad, explotación y rentas. El clero regular Zaragozano en el siglo XVIII, Zaragoza, Diputación General de Aragón, 1998. También, para más información acerca del tema puede consultarse BARRIO GOZALO, Maximiliano: Segovia, ciudad conventual. El clero regular al final del Antiguo Régimen (1768 - 1836), Valladolid, Universidad de Valladolid, 1995.; y LÓPEZ MARTÍNEZ Antonio Luis: La economía de las órdenes religiosas en el Antiguo Régimen. Sus propiedades y rentas en el reino de Sevilla, Sevilla, Diputación Provincial, 1990.

27 BARRIO GOZALO, Maximiliano: "Sociedad, Iglesia y vida religiosa en el siglo XVIII. Notas para un estudio demográfico - económico y socio - religioso”. Anthologica Annua 36,1989, p. 291. 
El convento agustino de Cádiz es un claro exponente de esto, pues tuvo más de 50 viviendas asentadas en las calles más valoradas de la ciudad. Tanto en los libros de ingreso como en el inventario de los bienes del convento fechado en 1835 , se mencionan estas moradas. Fueron las siguientes: viviendas en las calles Rosario, San Javier, Espíritu Santo, Herrón, Amargura, Las Comedias, Verónica, Linares y Plaza San Francisco. En la calle Herrón, tuvo una vivienda sita en el n. ${ }^{\circ}$ 86, que heredó del capitán D. Matías Paredes, muerto sin hijos. De la herencia de D. ${ }^{a}$ Manuela de la Paz recibieron una casa en la calle Rosario. Tuvo otra casa en la misma calle enfrente de la Plazuela de San Francisco y capilla de Loreto, que compró el convento al racionero Melchor Izquierdo. En 1791 se hizo con varias casas en la calle Las Comedias con los nn. ${ }^{\circ}$ 19, 46 y 53. La comunidad religiosa arrendó un par de casas de planta alta y baja en la calle Linares que en 1771 estuvieron cedidas a Antonio María Gavala; otra casa en la Plazuela de Loreto en el n. ${ }^{\circ}$ 107, con su cobertizo, dos pozos y pasillo principal; la casa se compró siendo prior Fr. Diego Jiménez y el vendedor fue el ya mencionado Melchor Izquierdo. Heredó la comunidad religiosa casa y capellanía en la Plaza de San Antonio a la muerte del capellán Pablo Álvarez Pimentel, presbítero y abogado en la ciudad de El Puerto de Santa María. La capellanía fue fundada por Pedro de la Cuesta en 1675, según consta en escritura de fundación del 10 de enero de dicho año ${ }^{28}$.

Poseyeron los agustinos de Cádiz más viviendas en las calles Camino, D. Julián Cortes, Los Descalzos, que heredó el convento de Agustina Gallegos; casa en la Plazuela del Mentidero, n. ${ }^{\circ} 90$ y la mitad de una casa y medio pozo en la calle Rosario que el convento recibió de Ana y Josefa Sierra, dada en 1775 a Manuel Conteca en censo; casa en la Plazuela de Tomás del Lino que recibieron de la herencia de Tomasa y María La Bella ${ }^{29}$; Plazuela del Correo; calle Rosario esquina a La Verónica, n. ${ }^{\circ}$ 174; San Francisco Javier, nn. ${ }^{\circ} 118$ a 121; Huerto Perdido, n. ${ }^{\circ} 122 ;$ Sal, n. ${ }^{\circ} 158$; Rosario, nn. ${ }^{\circ} 72$ y 73; una manzana de casas frente al teatro con los nn. ${ }^{\circ}$ 45, 46, 19 y 53; Barba, n. ${ }^{\circ}$ 65; Calvario, n. ${ }^{\circ} 135$; Sacramento, nn. ${ }^{\circ} 175$ y 175 1/2 ; Emperador, n. ${ }^{\circ}$ 115; Ancha, n. ${ }^{\circ}$ 75; Plazuela de la Cruz de la Verdad, n. ${ }^{\circ}$ 90; Amargura, n. ${ }^{\circ}$ 99; Ángel de la Bomba, n. 104; Camino, n. 74; Linares, nn. 112 y 113; Alameda, n. ${ }^{\circ} 114$, Flamencos, n. ${ }^{\circ}$ 193; Torno de Santa María, n. ${ }^{\circ}$ 174; Zanja, n. 124; y Balsa de Tierra, n. ${ }^{\circ} 68{ }^{1 / 2}{ }^{30}$.

\footnotetext{
28 AHN. Clero. Secular - regular, legajo 1508.

${ }^{29}$ Ibidem.

${ }^{30}$ AHPCa. Hacienda. Caja 01235. Exp. 26.
} 
Las accesorias que fueron propiedad del convento gaditano también fueron cuantiosas. Tuvo dos moradas contiguas al convento y varias en la calles San Agustín con los nn. 8 al 12; Sol, nn. . 158, 159 y 160; Campo de Capuchinos, nn. ${ }^{\circ}$ 3, 4, 5 y 174; Verónica, n. ${ }^{\circ}$ 60; Marzal, n. ${ }^{\circ}$ 113, Torno de Santa María, n. ${ }^{\circ}$ 64; Zanja, n. ${ }^{\circ}$ 124; Plazuela de las Viudas, nn. 96 у 97; Manzana, nn. 89 у 31, Boquete, n. 153; Novena, n. ${ }^{\circ}$ 53; Carne, n. ${ }^{\circ}$ 19; Sacramento, nn. 165 y 165 1/2 ; Emperador, n. ${ }^{\circ}$ 215; y en la Callejuela del Correo otra accesoria en la casa antigua del Consulado ${ }^{31}$.

Destacó una propiedad en la calle Amoladores de la ciudad de Cádiz, con tienda de cristales y objetos de Alemania. El 31 de diciembre de 1777 se arrendó por 28 pesos mensuales a Antonio y José Preysler ${ }^{32}$.

\section{Cuadro 3}

Ubicación antigua y actual de las fincas urbanas que pertenecieron al convento San Agustín de Cádiz y que fueron edificadas en la ciudad ${ }^{33}$

\begin{tabular}{|c|c|}
\hline Antigua denominación de la calle & Denominación actual de la calle \\
\hline Plaza de San Antonio & Plaza de San Antonio \\
\hline Capitán Julián Cortés & Isabel la Católica \\
\hline Huerto Perdido & $\begin{array}{l}\text { Barranquilla de Lope - Doctor Marañón - } \\
\text { José de Dios - Hospital de Mujeres }\end{array}$ \\
\hline Carne & Columela \\
\hline Emperador & Arbolí \\
\hline Rosario & Rosario \\
\hline Ancha & Ancha \\
\hline Plazuela de Loreto & San Francisco \\
\hline San Francisco Javier & San Francisco Javier \\
\hline La Amargura & Sagasta \\
\hline Camino & Isabel la Católica \\
\hline Plaza del Correo & San Agustín \\
\hline Sacramento & Sacramento \\
\hline Comedias & Feduchy \\
\hline La Verónica & José del Toro \\
\hline Alameda & Alameda Marqués de Comillas \\
\hline Herrón & Hospital de Mujeres \\
\hline Ángel de la Bomba & Nava \\
\hline Las Descalzas & Montañés \\
\hline Calvario & Calderón de la Barca \\
\hline Cruz de la Verdad & Mentidero \\
\hline Torno de Santa María & Teniente Andújar \\
\hline
\end{tabular}

31 Ibidem.

32 AHN. Clero. Secular - regular, legajo 1504.

33 ARIZA ASTORGA, Juan José: Cronología de las denominaciones de las calles de Cádiz, en línea http://blogs.grupojoly.com/con-la-venia/files/2012/05/Cronologia-de-las-denominaciones-de-las-calles-deCadiz.pdf, 2012. Consultado el 20 - 09 - 2019. 


\begin{tabular}{|c|c|}
\hline Plazuela de las Viudas & Viudas \\
\hline Amoladores & Churruca \\
\hline Campo de Capuchinos & Cerca de Capuchinos \\
\hline Marzal & Vea - Murgía \\
\hline Novena & Novena \\
\hline Sacramento & Sacramento \\
\hline Don Carlos & Carlos III \\
\hline Flamencos & Flamenco \\
\hline Los Linares & Buenos Aires \\
\hline Boquete & Plocia \\
\hline Sol & Mirador \\
\hline Ángel & .Angel \\
\hline Zanja & Benjumea \\
\hline Mateo Alba & Mateo Alba \\
\hline Bolsa del Fiero & Sargento Daponte \\
\hline
\end{tabular}

Tuvo la comunidad una casa en la calle La Campana de Jerez de la Frontera. En la villa de Puerto Real (Cádiz) tuvieron una casa en la calle San Antonio, esquina calle Nueva, con una medida de $12 \frac{1}{2} 2$ varas al frente y 24 al fondo $^{34}$. En Chiclana de la Frontera recibieron otra casa de la herencia de Juan Bautista y su mujer Sebastiana Pérez, por el testamento que éstos hicieron el 5 de febrero de $1801^{35}$.

Estas moradas fueron en su mayoría arrendadas a particulares.

\section{Cuadro 4}

Rentas de alquileres de las casas propiedad del convento San Agustín de Cádiz $(1815)^{36}$

\begin{tabular}{|c|c|}
\hline \multicolumn{2}{|c|}{ Año 1815} \\
\hline Enero - abril & 118.697 rs. y $22 \mathrm{mrs}$. \\
\hline Mayo - agosto & 118.316 rs. y $5 \mathrm{mrs}$. \\
\hline Septiembre - diciembre & 135.852 rs. y $25 \mathrm{mrs}$. \\
\hline
\end{tabular}

\section{Cuadro 5}

Rentas de alquileres de las casas propiedad del convento San Agustín de Cádiz $(1820)^{37}$

\begin{tabular}{|c|c|}
\hline \multicolumn{2}{|c|}{ Año 1820} \\
\hline Enero - abril & 110.084 rs. y 3 mrs. \\
\hline Mayo - agosto & 118.316 rs. y $5 \mathrm{mrs}$. \\
\hline Septiembre - diciembre & 135.851 rs. y $25 \mathrm{mrs}$. \\
\hline
\end{tabular}

34 AHN. Clero. Secular - regular, legajo 1510.

35 AHN. Clero. Secular - regular, legajo 1508.

36 AHN. Clero. Secular - regular, libro 1789, ff. 4 v - r, 12 r.

${ }^{37}$ Ibid., ff. 60 r, 64v, 69v. 


\section{Cuadro 6}

Rentas de alquileres de las casas propiedad del convento San Agustín de Cádiz $(1828)^{38}$

\begin{tabular}{|c|c|}
\hline \multicolumn{2}{|c|}{ Año 1828} \\
\hline Enero - abril & 62.338 rs. y $1 \mathrm{mrs}$. \\
\hline Mayo - agosto & 57.461 rs. y $3 \mathrm{mrs}$. \\
\hline Septiembre - diciembre & 52.571 rs. y $16 \mathrm{mrs}$. \\
\hline
\end{tabular}

b) Bienes rústicos.

Respecto de la explotación agraria, generalmente los eclesiásticos utilizaron dos formas de rentabilidad de sus propiedades: el cultivo directo, el arrendamiento y la cesión a tributo perpetuo. El cultivo directo de una parte sus fincas fue una praxis muy común. Esto explica que en sus libros de cuentas se encuentren partidas de gastos relacionadas con el trabajo directo de la tierra, como el salario que se abonó a los criados que la cultivaron. Sin embargo, la mayor parte de la tierra se arrendó a terceros mediante diferentes tipos de contratos agrarios ${ }^{39}$.

Este convento no poseyó demasiadas tierras. De éstas destacaron: las fincas de cereal en el sitio llamado Almedrillo, en la villa de Lepe ${ }^{40}$, y las tierras y pinares ubicadas en la jurisdicción de Puerto Real ${ }^{41}$. En la Real Isla de El León (San Fernando) fueron dueños de una hacienda de campo conocida con el nombre de San Agustín, compuesta de viñas, huertas, jardines, plantíos, salinas y casa. Estuvo arrendada en 1817 a Lucas Carrasco por el precio de 3.244 reales de vellón ${ }^{42}$.

\section{c) Los censos.}

Los censos fueron la única fórmula de préstamo a interés moralmente aceptada en el Antiguo Régimen, ya que no suponían usura, por lo que fueron ampliamente utilizados por todos los sectores sociales, incluida la Iglesia. Además, y dado que la venta de los bienes era prácticamente imposible por la existencia de vinculaciones y mayorazgos, en caso de requerir moneda corriente, lo usual fue recurrir a este tipo de préstamos hipotecarios ${ }^{43}$.

\footnotetext{
38 Ibid., ff. 157r, 164 v, 184r.

39 BARRIO GOZALO, Maximiliano: "Sociedad, Iglesia y vida religiosa en el siglo XVIII...", p. 288. Véase también LÓPEZ MARTÍNEZ, Antonio Luis: "La empresa agraria monástica en Andalucía. Gestión de las explotaciones agrarias de la Orden de la Cartuja (siglos XV - XIX)”. Hispania 57, n. ${ }^{\circ}$ 196, 1997, p. 713.

40 AHN. Clero. Secular - regular, legajo 1510.

${ }^{41}$ AHN. Clero. secular - regular, legajo 1504.

42 AHN. Clero. Secular - regular, libro 1789.

${ }^{43}$ RODRÍGUEZ PÉREZ, M. A: "Censos y tributos: los conventos de Santa Cruz de la Palma en el Antiguo

Régimen y sus economías”. Revista de Estudios Generales de la Isla de La Palma 2, 2006, pp. 395- 430
} 
Esta clase de tributos recayeron sobre todo tipo de haberes e inmuebles: casas, tierras, edificios públicos... La comunidad cobró impuestos sobre casas situadas en las siguientes vías de la ciudad: Plazuela Nueva, n. ${ }^{\circ}$ 165; Juan Andrés, n. ${ }^{\circ} .159 ;$; Plazuela de las Nieves, n. ${ }^{\circ}$ 121; Mirador, n. ${ }^{\circ}$ 12; callejón bajo de los Descalzos, n. ${ }^{\circ}$ 16; Amargura, n. ${ }^{\circ}$ 11; Capuchinos, n. ${ }^{\circ}$ 91; Cobos, n. ${ }^{\circ} 5$ y Esquina de las Flores, n. ${ }^{\circ}$ 5. Mantuvo un censo sobre el Hospital del Carmen y otros dos sobre un par de casas de religiosos: convento de la Victoria de El Puerto de Santa María y el convento de San Francisco de la ciudad. Igualmente las cargas recayeron en varios patronatos: Patronato de Segura, pagado por la catedral; patronato de Flagela, también sufragado por la catedral, Patronato de Fuentes y de Armesto.

La cuantía que aportaron estas tasas a la comunidad agustina de Cádiz fue muy abundante. En el año 1822 fueron un total de 14.228 reales y 63 maravedíes; y en 1831 un total de 12.872,61 reales de vellón.

\section{d) Patronatos.}

El concepto de patrón o patrono apunta a protección, a defensa y amparo, pero también remite a las nociones de poder y de superioridad, ideas y realidades que en el mundo feudal y tardofeudal entroncarán con las categorías nobiliar y señorial. El patronazgo vino a formar parte de las cualidades de la nobleza: destilaba preeminencia, supremacía, distinción, magnanimidad, paternalismo, piedad... atributos todos ellos que se pretendieron característicos y propios de la nobleza y los señores. En aquella sociedad tan imbuida de religiosidad y referencias sagradas, el patronazgo y la protección se orientaron de una forma predominante hacia el mundo eclesiástico y religioso. Realmente durante el Antiguo Régimen ninguna familia de la nobleza que se preciara desechó la oportunidad de ejercer su patronato sobre una o más entidades eclesiásticas: conventos y monasterios, colegiatas, capillas y capellanías, iglesias parroquiales, curatos, obras pías, hospitales... fueron objeto de la actividad patrocinadora que desplegaron tantas y tantas familias de la aristocracia y de los poderosos locales, llegando a conformar en ocasiones nutridas redes de patronato que casi siempre se incorporaban en las fundaciones de mayorazgos. Incluso, en ese frenesí de patrocinio, también capítulos y provincias de las órdenes religiosas vinieron a formar parte de los elementos susceptibles de acogerse a un patrón. Normalmente el acceso a un patronato conventual se formalizaba a través de una escritura de concesión de patronato en la que se articulaban las condiciones del mismo y/o a través de la concesión del título de patrón que hacían oficial los órganos de gobierno de la orden religiosa respectiva. También hubo casos en los que las familias nobles se adjudicaron el patronato por la vía de los hechos, casos en 
los que tal título se impuso de forma efectiva sin que mediaran formalidades documentales o jurídicas. Los representantes de las oligarquías locales y de sectores que podemos calificar de poderosos y nobles no titulados pudieron acceder al título de patrono de conventos ya instalados y fundados por otros agentes o instancias, aunque parece que lo hicieron con menor intensidad que los primeros ${ }^{44}$.

El convento San Agustín de Cádiz - como ya ha quedado expresado anteriormenteofreció el patronato de las capillas de la iglesia a personas e instituciones de alto calado social en la ciudad, espacios que fueron reservados para sus enterramientos y oficios religiosos. El libro de recibo de misas correspondiente al año 1753, nos indica que en los meses de febrero y marzo la comunidad cobró 56 reales por el patronato de los Yriberri; y entre noviembre y diciembre del mismo año, 2.799 reales por el de los Aróstegui ${ }^{45}$.

e) Misas.

Las obligaciones religiosas que cargaron sobre los agustinos de Cádiz fueron muy numerosas. En este apartado se sitúan las celebraciones de misas cantadas, rezadas, vigilias, misas de fiestas, novenarios... Todas estas conmemoraciones fueron muy cuidadas, pues en ocasiones se llegaron a contratar acólitos y organistas que hicieran que las ceremonias fueran más solemnes.

Cada uno de estos oficios fue anotado escrupulosamente en los libros de misas, así como la gratificación recibida por cada celebración. El libro de misas del año 1790 nos los detalla de la siguiente manera, semana por semana. Expongo un ejemplo de ello:

\section{Cuadro 7}

Misas celebradas en el convento San Agustín de Cádiz durante el mes de octubre de $1790^{46}$

\begin{tabular}{|c|c|}
\hline Semana & Misas celebradas \\
\hline Sábado 2 de octubre de & Se han dicho en esta semana cincuenta misas rezadas y \\
& veinte cantadas, de éstas aplicamos una por el entierro del \\
& alcalde mayor D. Gaspar de Anavida, y las diecinueve las \\
& aplicamos por las cargas del convento. De las rezadas, \\
& aplicamos once para la sacristía, correspondientes a esta \\
& semana, veinticinco por el P. Fr. Juan Helendo, que murió el \\
& Huelma. Recibimos por las dieciocho misas setenta y dos \\
& reales \\
\hline
\end{tabular}

44 ATIENZA LÓPEZ, Ángela: "La apropiación de patronatos conventuales por nobles y oligarcas en la Edad Moderna”. Investigaciones Históricas 28, 2008, pp. 80, 87.

45 AHN. Clero. Secular - regular, libro 1788.

46 AHN. Clero. Secular - regular, libro 1786. 


\begin{tabular}{|c|c|}
\hline $\begin{array}{c}\text { Sábado } 9 \text { de octubre de } \\
1790\end{array}$ & $\begin{array}{l}\text { Se han dicho en esta semana cincuenta misas rezadas y } \\
\text { veintiuna cantadas, de éstas, aplicamos una por el P. Antonio } \\
\text { Bustillo que murió de prior en Écija y las veinte restantes las } \\
\text { aplicamos por las cargas del convento. De las rezadas, } \\
\text { aplicamos once para la sacristía, correspondientes a esta } \\
\text { semana, veintitrés por el P. Prior de Écija y seis misas restantes } \\
\text { por la limosna que dio el P- Prior. Recibimos del P. Prior por } \\
\text { las dieciséis misas setenta y cuatro reales de vellón. }\end{array}$ \\
\hline $\begin{array}{c}\text { Sábado } 16 \text { de octubre de } \\
1790\end{array}$ & 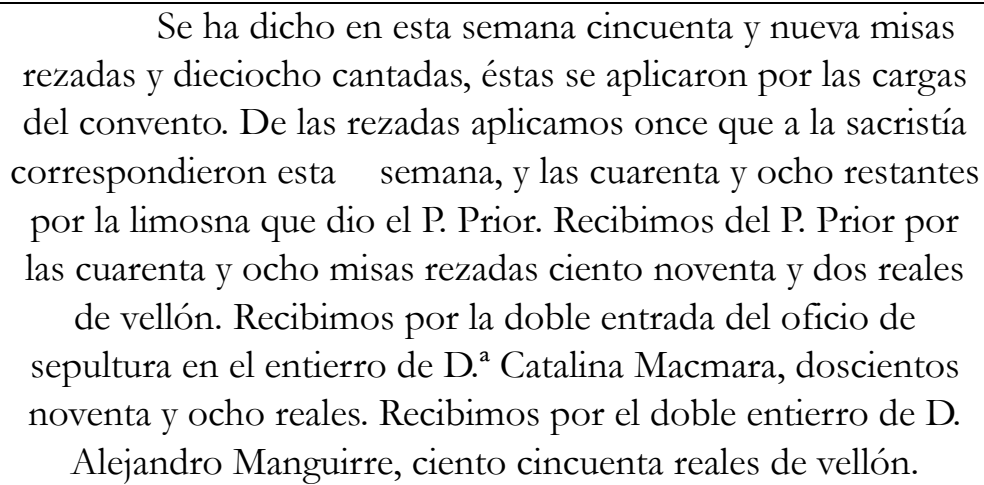 \\
\hline $\begin{array}{c}\text { Sábado } 23 \text { de octubre de } \\
1790\end{array}$ & 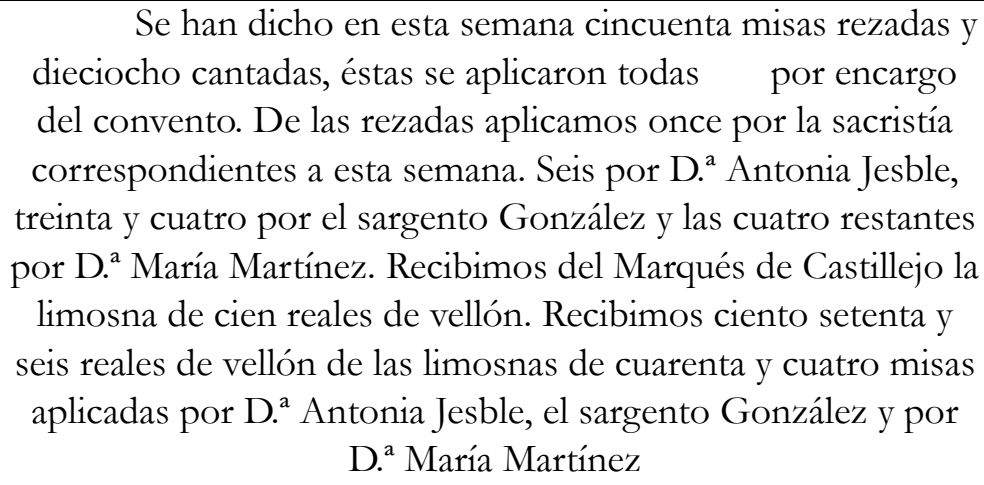 \\
\hline $\begin{array}{l}\text { Sábado } 30 \text { de octubre de } \\
1790\end{array}$ & $\begin{array}{l}\text { Se han dicho en esta semana cincuenta y siete misas } \\
\text { rezadas y dieciséis cantadas. De éstas, aplicamos tres por Fr. } \\
\text { Dionisio Sigi que murió en este convento, y las trece restantes } \\
\text { por cargos de este convento. De las rezadas aplicamos once } \\
\text { por la sacristía correspondientes a esta semana, y veinticuatro } \\
\text { por el P. Fr. Sigi, y las veintidós restantes las aplicamos por D. }{ }^{a} \\
\text { María Martínez. Recibimos ochenta y ocho reales de vellón de } \\
\text { las veintidós misas aplicadas por D. }{ }^{a} \text { María Martínez }\end{array}$ \\
\hline
\end{tabular}

El total de misas rezadas en el año 1790 fueron 5.535 y 887 cantadas $^{47}$.

f) Limosnas.

Los estipendios recibidos por la asistencia a celebraciones religiosas: predicaciones en fiestas, acompañamiento en los entierros - asistencia muy común -, procesiones ...; los cepillos colados en las capillas y esquinas de la iglesia, la generosidad de algunas personas y

${ }^{47}$ Ibidem. 
cofradías, la celebración de la Semana Santa y los devotos, aparecen con mucha frecuencia de los libros de recibo. Sabemos que con motivo del Jueves Santo, la Hermandad de los Vizcaínos entregó dinero a la comunidad para hacer la alfombra por la que pasaba el Santísimo; en el año 1753 la cantidad asignada fue de 555 reales. Las dádivas de los devotos fueron muy comunes y en algunos casos muy específicas. En diciembre de 1752 recibió la comunidad 1.824 reales de un fiel para la compra de siete barricas de tocino. En ocasiones los donativos fueron en especie, generalmente en trigo ${ }^{48}$.

\subsection{Los gastos}

Como en todas las casas, el capítulo de gastos también requirió una buena gestión. Analizando los libros de salidas del convento, el desembolso económico de la comunidad vino originado principalmente por las siguientes partidas: alimentación e indumentaria, salarios a los empleados - tema al que ya he hecho referencia en este trabajo -, gasto de culto y arreglo o reparación de los inmuebles, incluido el convento. También en ocasiones se suman partidas correspondientes a la compra de libros.

Por lo que respecta a la alimentación, el libro de gasto ordinario empezado el 7 de diciembre de 1755 y finalizado el 22 de diciembre de 1764, recoge de una manera muy detallada el gasto de la comunidad en manutención, pues describe el menú de la comida y de la cena día por día. Ésta, muy numerosa, consumió mucho pescado - cosa que no es de extrañar -, verduras y fruta, generalmente muy cara. Para las cenas un postre muy común fue las uvas con queso. En los días de las grandes fiestas, San Agustín, Santa Rita... tomaron chocolate - algo extraordinario - y algún que otro dulce.

Desde enero a marzo del año 1763 se gastaron un total de 4.655 reales y 48 maravedíes en la alimentación de los religiosos.

El gasto en indumentario no aparece elevado en las fuentes, siendo las prendas más costosas los hábitos, que en el año mencionado valió cada unidad unos 15 reales, y los zapatos.

Sí que fueron costoso los gastos relacionados con la reparación y embellecimientos de las casas y del convento. Las partidas económicas asignadas a carpinteros, herreros y albañiles aparecen con mucha frecuencia ${ }^{49}$.

\footnotetext{
48 Ibidem.

49 AHN. Clero. Secular - regular, libro 1778.
} 


\section{Conclusión}

Empleando diversas fuentes bibliográficas y otros recursos de investigación - como el empleo de fuentes inéditas -, he querido presentar un estudio de la economía del convento San Agustín de Cádiz (1750 - 1835). Al mismo tiempo, estoy convencido de que también oferto un aporte más para la historiografía del tema de las economías monásticas, tan variado como diferentes fueron las numerosas regiones nacionales en la que se edificaron las cuantiosas casas religiosas. Así, por ejemplo, no es lo mismo un convento levantado en una zona portuaria - comercial y de paso a nuevas tierras descubiertas - como el caso que nos ocupa - y, por tanto, resulta ser de primer orden de cara a su ejercicio económico los alquileres de viviendas urbanas y las fundaciones religiosas; que un convento edificado en una zona rural, donde las fincas y los productos agrarios ocupan el primer puesto.

A partir de los libros de Apeos, testamentos, el Catastro de Ensenada, Libros Becerros e Inventarios, he podido anotar las propiedades del convento así como la situación económica del mismo. El estudio de éstos, nos demuestra cómo el convento de Cádiz fue un auténtico "señor nobiliario", quizá no por voluntad de los agustinos calzados - frailes mendicantes - pero sí por la libre disposición y condición social de los donantes y testadores. Hecho, que nos demuestra al mismo tiempo, la gran incidencia que tuvo la comunidad religiosa en el seno de la sociedad gaditana. Un detalle muy significativo, es que los ingresos de la comunidad por los conceptos de acompañamientos a entierros y novenas populares fueran muy notables, los cual corrobora la afirmación anterior que parte del deseo de los frailes por inmiscuirse entre las gentes.

En todas las fuentes consultadas se expresa de manera clara cómo la gran cantidad de inmuebles urbanos fue la gran riqueza que permitió el mantenimiento del convento y de la comunidad religiosa.

La forma tan precisa y esmerada con la que se escribe y por tanto se refleja todo lo referente al ejercicio económico del convento, nos demuestra el gran interés que tuvieron estos religiosos por una buena administración, consolidación y ampliación del patrimonio conventual - como así se hizo - y que permitirá la consolidación de una comunidad religiosa que en algunos momentos fue muy numerosa, pasando de 80 frailes.

Tan abundante patrimonio amortizado, sinónimo de riqueza en una subasta al mejor pujante, fue objetivo directo de la desamortización de Mendizábal, cuyos fines intentaron 
paliar la deuda pública y llevar a cabo una reforma agraria ${ }^{50}$. Estos bienes a los que he hecho mención a largo del estudio, fueron sacados a pública licitación y adjudicados al mejor postor. En los Boletines Oficiales de la Venta de Bienes Nacionales, se menciona la venta, tasación y adjudicación de algunas propiedades del convento San Agustín de Cádiz.

\section{Cuadro 8}

Tasación, venta y adjudicación de las propiedades urbanas del convento San Agustín de Cádiz en los Boletines Oficiales de Venta de Bienes Nacionales

\begin{tabular}{|c|c|c|c|c|c|c|}
\hline $\begin{array}{c}\text { Fechas de la } \\
\text { licitación }\end{array}$ & $\begin{array}{l}\text { Bienes } \\
\text { rústicos }\end{array}$ & $\begin{array}{c}\text { Valor } \\
\text { tasación } \\
51\end{array}$ & $\begin{array}{l}\text { Valor } \\
\text { remate }\end{array}$ & $\begin{array}{l}\text { Bienes } \\
\text { urbanos }\end{array}$ & $\begin{array}{c}\text { Valor } \\
\text { tasación }\end{array}$ & $\begin{array}{l}\text { Valor } \\
\text { remate }\end{array}$ \\
\hline $\begin{array}{l}\text { Del } 16 \text { / V / } 1836 \\
-16 / \text { V / } 183752\end{array}$ & 2 & $\begin{array}{c}181.529 \\
\text { rs. }\end{array}$ & $\begin{array}{l}325.000 \\
\text { rs. }\end{array}$ & 23 & $\begin{array}{l}2.356 .920 \\
\text { rs. }\end{array}$ & $\begin{array}{c}4.373 .636 \\
\text { rs. }\end{array}$ \\
\hline $\begin{array}{l}\text { Del } 18 \text { / IV / } 1837 \\
-16 \text { / III / } 1838^{53} \\
\end{array}$ & 0 & 0 rs. & 0 rs. & 3 & $\begin{array}{c}158.401 \\
\text { rs. }\end{array}$ & $\begin{array}{c}255.500 \\
\text { rs. }\end{array}$ \\
\hline $\begin{array}{c}\text { Del } 16 \text { / III / } 1838 \\
\text { - 5 / V / } 183954\end{array}$ & 0 & 0 rs. & 0 rs. & 3 & $\begin{array}{c}147.977 \\
\text { rs. }\end{array}$ & 45.025 rs. \\
\hline $\begin{array}{c}\text { Del } 13 \text { / IV / } 1839 \\
-15 \text { / II / } 1840\end{array}$ & 1 & --- & $\begin{array}{l}120.080 \\
\text { rs. }\end{array}$ & 2 & --- & $65.315 \mathrm{rs}$. \\
\hline $\begin{array}{c}\text { Del } 15 \text { / IX / } 1841 \\
-9 \text { / III / } 184355 \\
\end{array}$ & 0 & 0 rs. & 0 rs. & 3 & $\begin{array}{c}103.922 \\
\text { rs. }\end{array}$ & 90.000 rs. \\
\hline $\begin{array}{c}\text { Del } 6 \text { / VIII / } \\
1855 \text { - } 29 \text { / VI / } \\
1856^{56}\end{array}$ & 0 & 0 rs. & $0 \mathrm{rs}$. & 1 & $\begin{array}{l}832.032 \\
\text { rs. }\end{array}$ & --- \\
\hline
\end{tabular}

El convento de Cádiz a partir de las disposiciones gubernamentales desamortizadoras de 1835 no sólo no fue perdiendo su inmenso patrimonio para siempre, sino también la presencia de estos religiosos hasta el año 1915.

${ }^{50}$ CÁRCEL ORTÍ, Vicente: "El liberalismo en el poder (1833 - en 1868)", en R. GARCÍA VILLOSLADA (dir.): Historia de la Iglesia en España. La iglesia en la España Contemporánea, Madrid, BAC, 1969, p. 139. Para la Real Orden puede consultarse CAMPOS Y FERNÁDEZ DE SEVILLA, Francisco Javier: "Textos legales de las desamortizaciones eclesiásticas españolas y con ellas relacionadas" en F. J. CAMPOS Y FERNADEZ DE SEVILLA (coord.), La desamortización: el expolio del patrimonio artístico y cultural de la Iglesia en España: actas del Simposium 6/9 - IX- 2007, San Lorenzo de El Escorial, Ediciones Escurialenses - Real Colegio Universitario María Cristina, 2007, p. 16.

${ }^{51}$ El valor total de la tasación y el remate que expongo en el texto son la suma total de las cuantías que aparecen reflejadas en los Boletines de Ventas. De ahí que en ocasiones el valor de remate sea inferior al de tasación, cuando lo normal es que sea lo contrario.

52 AHN. Fondos Contemporáneos. Ministerio de Hacienda. B - V. n. ${ }^{\circ} 1$ (nn. 1 - 200). Los compradores de algunos de estos bienes fueron: Antonio Ruiz, Pedro Pascual, José María Navarro y Julián López.

${ }_{53}$ AHN. Fondos Contemporáneos. Ministerio de Hacienda. B - V. n. ${ }^{\circ} 2$ (nn. 201 - 394).

54 AHN. Fondos Contemporáneos. Ministerio de Hacienda. B - V. n. ${ }^{\circ} 3$ (nn. 398 - 529).

55 AHN. Fondos Contemporáneos. Ministerio de Hacienda. B - V. nn. 7 (nn. ${ }^{\circ} 801$ - 1000), n. ${ }^{\circ} 9$ (nn. 1001 1117), n. ${ }^{\circ} 12$ (1201 - 1400). Todo el tiempo que abarcó la regencia del general Espartero.

${ }^{56}$ AHN. Fondos Contemporáneos. Ministerio de Hacienda. B - V. n. 24 (nn. ${ }^{\circ} 1$ - 296). Durante el Bienio Progresista salió a remate el edificio conventual de tres pisos, a excepción de la iglesia y sacristía. 


\section{Bibliografía}

ARIES, Philippe: El hombre ante la muerte, Madrid, Taurus, 1987.

ATIENZA LÓPEZ, Ángela: Propiedad y señorío en Aragón. El clero regular ante la expansión de la crisis (1700 - 1835), Zaragoza, Institución Fernando el Católico, 1993.

ATIENZA LÓPEZ, Ángela: Propiedad, explotación y rentas. El clero regular Zaragozano en el siglo XVIII, Zaragoza, Diputación General de Aragón, 1998.

ATIENZA LÓPEZ, Ángela: "La expansión del clero regular en Aragón durante la Edad Moderna. El proceso fundacional". Anuario de Historia Moderna 21, 2000.

ATIENZA LÓPEZ, Ángela: "La apropiación de patronatos conventuales por nobles y oligarcas en la Edad Moderna”. Investigaciones Históricas 28, 2008.

BARRIO GOZALO, Maximiliano; Segovia, ciudad conventual. El clero regular al final del Antiguo Régimen (1768 - 1836), Valladolid, Universidad de Valladolid, 1995.

BARRIO GOZALO, Maximiliano: "Sociedad, Iglesia y vida religiosa en el siglo XVIII. Notas para un estudio demográfico - económico y socio - religioso". Anthologica Annua 36,1989.

CAMPOS Y FERNÁNDEZ DE SEVILLA, Francisco Javier: "Textos legales de las desamortizaciones eclesiásticas españolas y con ellas relacionadas" en F. J. CAMPOS Y

FERNÁNDEZ DE SEVILLA (coord.), La desamortización: el expolio del patrimonio artístico y cultural de la Iglesia en España: actas del Simposium 6/9 - IX-2007, San Lorenzo de El Escorial, Ediciones Escurialenses - Real Colegio Universitario María Cristina, 2007.

CÁRCEL ORTÍ, Vicente: “El liberalismo en el poder (1833 - en 1868)”, en R. GARCÍA VILLOSLADA (dir.): Historia de la Iglesia en España. La iglesia en la España Contemporánea, Madrid, BAC, 1969.

FERNÁNDEZ GARCÍA, Antonio et alii (coords.): Historia Universal. Edad Contemporánea, Barcelona, Vicens Vives, 2000.

ESTRADA ROBLES, Basilio: Los agustinos ermitaños en la España hasta el siglo XIX, Madrid, Editorial Revista Agustiniana, 1988.

HOROZCO, Agustín de: Historia de la Ciudad de Cádiæ, Cádiz, Ayuntamiento de Cádiz, 1845.

LÓPEZ MARTÍNEZ Antonio Luis: La economia de las órdenes religiosas en el Antiguo Régimen. Sus propiedades y rentas en el reino de Sevilla, Sevilla, Diputación Provincial, 1990.

LÓPEZ MARTÍNEZ, Antonio Luis: "La empresa agraria monástica en Andalucía. Gestión de las explotaciones agrarias de la Orden de la Cartuja (siglos XV - XIX)". Hispania 57, n. ${ }^{\circ} 196$ (1997).

LÓPEZ OLLERO, María Ángela: Los bienes del clero regular en la provincia de Cádiz en vísperas de la desamortización de Mendizábal [Tesis doctoral leída en la Universidad de Sevilla], 1999.

MADOZ, Pascual: Diccionario Geográfico - Estadístico - Histórico de España y sus posesiones de Ultramar, V, Madrid, Imprenta Nacional, 1846.

MARTÍN GUTIÉRREZ, Emilio: "Nuevos datos sobre la población y los genoveses en la ciudad de Cádiz. Una relectura de padrón de vecinos de 1467”, En La España Medieval, 29, 2006

MARTÍNEZ RUIZ, Enrique: Elpeso de la Iglesia. Cuatro siglos de órdenes religiosas en España, Madrid, Actas, 2004.

MIRANDA MENACHO, Vera Cruz: "Algunos aspectos de la economía del monasterio de Pedralbes a través del Manual (1414 - 1419) y del Capbreu (1414 - 1418) de Gabriel de Forest". Anuario de Estudios Medievales 33/1 (2003).

MORGADO GARCÍA, Arturo: La diócesis de Cádiæ: De Trento a la desamortización, Cádiz, Servicio de Publicaciones de la Universidad de Cádiz, 2008. 
RODRÍGUEZ PÉREZ, M. A: "Censos y tributos: los conventos de Santa Cruz de la Palma en el Antiguo Régimen y sus economías". Revista de Estudios Generales de la Isla de La Palma 2, 2006. RUIZ GARZÓN, Gabriel: "Reseña de la Memoria de la estadística de la provincia de Cádiz de Adolfo de Castro (1862)", en J. M. a ARRIBAS MACHO et alii (coords.): Jornadas de Historia de la Estadística y Probabilidad VI, junio de 2011, Valencia, UNED, 2012.

SAAVEDRA, Pegerto: "El control de los patrimonios eclesiásticos en la Galicia Moderna". Historia Agraria 74 (2018).

SÁNCHEZ MECO, Gregorio: El Escorial y la orden jerónima. Análisis económico - social de una comunidad religiosa, Madrid, Patrimonio Nacional, 1985.

SORIANO TRIGUERO, Carmen: "La propiedad inmobiliaria de los conventos femeninos madrileños del siglo XVIII". Cuadernos de Historia Moderna, 24, 2000. 